\title{
DESENVOLVIMENTO SUSTENTÁVEL E ECOLOGIA POLITICA COMO ECO- CIDADANIA EM LUIS ALBERTO WARAT: UMA EXPERIÊNCIA DO MOVIMENTO DAS MULHERES CAMPONESAS
}

\section{Neusa Schnorrenberger ${ }^{1}$}

Resumo: As mulheres no ambiente rural têm uma preocupação maior, em especial na questão do cuidado ecológico e com o desenvolvimento sustentável, uma vez que o meio em que estão inseridas, faz com que elas estejam mais próximas com a terra e a produção de alimentos . Neste sentido, o presente texto procura analisar a relação existente entre desenvolvimento sustentável e ecologia política como eco-cidadania em Warat correlacionando a experiência das mulheres camponesas e o meio ambiente ecológico, buscando evidenciar desdobramentos do desenvolvimento sustentável também por meio da ecologia política e eco-cidadania como uma prática alternativa pelas mulheres camponesas.

Palavras-chave: Desenvolvimento Sustentável; Eco-Cidadania; Ecologia Política; Luís Alberto Warat; Mulheres Camponesas.

\section{SUSTAINABLE DEVELOPMENT AND POLITICAL ECOLOGY AS ECO- CITIZENSHIP IN LUIS ALBERTO WARAT: AN EXPERIENCE OF THE PEASANT WOMEN'S MOVEMENT}

\begin{abstract}
Women in the rural environment have a greater concern, especially in the issue of ecological care and sustainable development, since the environment in which they are inserted, causes them to be closer to the land and food production. In this sense, the present text seeks to analyze the relationship between sustainable development and political ecology as eco-citizenship in Warat, correlating the experience of peasant women and the ecological environment, seeking to evidence unfolding of sustainable development also through political ecology and eco- citizenship as an alternative practice for peasant women.
\end{abstract}

Keywords: Sustainable Development; Eco-Citizenship; Political Ecology; Luís Alberto Warat; Peasant Women.

\section{INTRODUÇÃO}

A preocupação em relação ao ecológico é uma realidade, demonstrado inclusive pelas mulheres camponesas que inseridas em movimentos de mulheres do campo, reivindicam

\footnotetext{
${ }^{*}$ Mestranda em Direito no PPGD - Mestrado e Doutorado/ URI, Campus Santo Ângelo-RS. Bacharel em Direito pela Universidade Regional Integrada do Alto Uruguai e das Missões (URI), Campus Santo Ângelo-RS. Integrante do Grupo de Pesquisa "Direitos de Minorias, Movimentos Sociais e Políticas Públicas", vinculado ao PPGD, acima mencionado. Bolsista CAPES.E-mail: asuensch@ hotmail.com
} 
melhores condições de vida para si e suas famílias e emancipação, invocando premissas de desenvolvimento sustentável intergeracional, bem como uma autonomia em relação as suas próprias vidas. Assim questiona-se como o desenvolvimento sustentável e a ecologia política, como uma eco-cidadania nos moldes waratianos, está relacionada ao Movimento das Mulheres Camponesas.

Para sustentação argumentativa e teórica do objetivo central dessa pesquisa, acima exposto, este trabalho irá utilizar estudos sociológicos, através da pesquisa bibliográfica, embasada no método de abordagem dedutivo. Para o desenvolvimento desse estudo, num primeiro momento o texto se aterá a discorrer sobre o entendimento de desenvolvimento sustentável, a fim de se perceber como ocorre essa correlação entre a preocupação ecológica e as mulheres camponesas, para, num segundo momento, averiguar o entrelaçamento da ecologia política como uma eco-cidadania waratiana e, por último, analisar-se-á o Movimento das Mulheres Camponesas e a eco-cidadania como um novo viés emancipatório.

\section{ASPECTOS SOBRE O DESENVOLVIMENTO SUSTENTÁVEL}

O direito ao meio ambiente ecologicamente equilibrado, como um direito fundamental, está previsto no art. 225 da Constituição da República Federativa do Brasil de 1988, conhecido como norma matriz do Direito Ambiental brasileiro (BRASIL, 1988) e até a implementação na Constituição Federal de 1988 (CF/1988) do denominado Estado Socioambiental houve um longo caminhar, com o desenvolver de três gerações cumulativas e complementares de dimensões de direitos (SARLET, 2007, p. 54). O referido dispositivo constitucional acaba por enaltecer a necessidade de implementação de um Estado Socioambiental de Direito, que se apresenta como um modelo de Estado no qual em que esteja compatibilizada a "[...] atividade econômica com a ideia de desenvolvimento (e não apenas crescimento!) sustentável, de modo que a 'mão invisível' do mercado seja substituída pela 'mão visível' do Direito [...]”' (SARLET; FENSTERSEIFER in SARLET [Org.], 2010, p. 21).

Na mesma senda, Bobbio apregoa sobre a necessidade de se pensar o desenvolvimento de forma intergeracional, quando afirma: "Olhando para o futuro, já podemos entrever a 
extensão da esfera do direito à vida das gerações futuras, cuja sobrevivência é ameaçada pelo crescimento desmensurado de armas cada vez mais destrutivas [...]" (BOBBIO, 2004, p. 59). Em razão disso, imperioso se faz o estudo acerca do desenvolvimento sustentável no cenário contemporâneo e a busca de que o mesmo seja visto de forma integrada e sistêmica.

Mister se faz trazer à baila que a categoria de desenvolvimento sustentável é uma importante manifestação principiológica encontrada no texto constitucional brasileiro, que abarca o cunho ideológico de outros documentos internacionais. Já na Conferência Mundial de Meio Ambiente ocorrida no ano de 1972, em Estocolmo, depreende-se um leve discurso de sustentabilidade em suas disposições, porém, o conceito foi utilizado pela primeira vez em 1987, no Relatório Brundtland, redigido pela Organização das Nações Unidas (ONU). ${ }^{2}$ A terminologia "desenvolvimento sustentável" recebeu todo o destaque merecido na Conferência do Meio Ambiente e Desenvolvimento das Nações Unidas (ECO-92/RIO-92) ${ }^{3} \mathrm{e}$ apresentada na forma de onze princípios ou diretrizes norteadoras da ação dos Estados, passando a ser difundidos em todas as demais conferências ambientais que se postergaram (FIORILLO, 2014, p. 70).

O princípio do desenvolvimento sustentável, de acordo com Fiorillo, objetiva alcançar três esferas: a econômica, social e ambiental. Para ele, "Busca-se com isso a coexistência harmônica entre economia e meio ambiente. Permite-se o desenvolvimento, mas de forma sustentável, planejada, para que os recursos hoje existentes não se esgotem ou tornem-se inócuos" (FIORILLO, 2014, p. 72). Porém, com um olhar mais crítico, José Rubens Morato Leite chama a atenção para o fato de que "A grande e talvez, a maior dificuldade em construir um Estado de Direito Ambiental é transforma-lo em um Estado de justiça ambiental” (LEITE in CANOTILHO; LEITE [Orgs.], 2012, p. 185). Para Flores e Trevizan,

O discurso da sustentabilidade do meio ambiente tem se tornado hegemônico, permeando desde mentes altruístas em defesa da conservação da natureza e da melhoria das condições de vida humana até aquelas que se utilizam desse mesmo discurso para se mostrarem simpáticas à opinião pública e dessa forma, tirar

\footnotetext{
2 De acordo com o Relatório Brundtland, também denominado "Nosso Futuro Comum" e que foi elaborado pela Comissão Mundial sobre Meio Ambiente e Desenvolvimento (CMMAD) da ONU e publicado em 1987, desenvolvimento sustentável "é aquele que atende às necessidades dos presentes sem comprometer a possibilidade de as gerações futuras satisfazerem suas próprias necessidades" (CMMAD, 1991, p. 46).

${ }^{3}$ A ECO-92 foi um grande evento em prol do meio ambiente, realizada em junho de 1992, no Rio de Janeiro (Brasil), reconhecida como "Cúpula da Terra", reunindo mais de 100 chefes de Estado do mundo para debater formas de desenvolvimento sustentável, norteando as discussões sobre um modelo de crescimento econômico menos consumista e mais preocupado com questões ambientais (SARLET; FENSTERSEIFER, 2014, p. 85).
} 
proveitos próprios. O certo é que organismos internacionais constatam que é grande e crescente o número de pessoas, movimentos, empresas e governos que buscam alternativas de atuação em conformidade com a sustentabilidade em suas diversas dimensões, resultantes dos movimentos de reformas sociais e políticas que, nas décadas de 1960 e 1970, questionaram as bases que sustentam a sociedade atual (FLORES; TREVIZAN,1999, p. 11).

É sob essa perspectiva que se compreende que devem ser rompidos drasticamente os laços com os antigos paradigmas que conduziram a sociedade mundial ao caos ecológico, pois "En realidad, la modernidad es responsable por una razón reduccionista, que en nombre de las certezas, trivializa la complejidad, dejando al hombre en la condición de un observador alienado, que se cree en la pose de un saber completo" (WARAT, 1997, p. 56). ${ }^{4}$ O ser humano não pode ser mero expectador de sua história, e, para isso, não pode ser educado para que assim seja. Essa educação diferenciada, que considera e valoriza as complexidades do meio ambiente natural, por sua vez, tem sido possibilitada pela perspectiva das mulheres camponesas, através do cuidado com o meio ambiente natural, oportunizado pelo seu conhecimento tradicional, adquirido culturalmente de geração em geração. E conforme a lição waratiana, "O meio ambiente não é o único que está sendo ameaçado de extermínio. $\mathrm{O}$ desastre ecológico é uma ameaça total ao ser humano. A convivência também está sendo ameaçada" (WARAT, 2010, p. 21), restando como um forte alerta. De outra banda, o escritor Henrique Leff, em sua obra "Ecologia, Capital e Cultura", reflete sobre os princípios capazes de propiciar o que se chama de desenvolvimento sustentável:

\begin{abstract}
Dos princípios da gestão ambiental e do manejo integrado de recursos emerge a possibilidade de construir uma economia mais equilibrada, justa e produtiva, uma economia baseada na diversidade biológica da natureza e na riqueza cultural da humanidade. Isso implicará a necessidade de legitimar os direitos e fortalecer politicamente as comunidades, dotando-as, ao mesmo tempo, de uma nova capacidade técnica, científica, administrativa e financeira para a autogestão de seus recursos produtivos e para tornar viável o manejo produtivo da biodiversidade, num projeto alternativo de desenvolvimento (LEFF, 2009, p. 83).
\end{abstract}

Neste sentido, no que tange as leis, Orci Paulino Bretanha Teixeira, refletindo sobre Estado de Direito Ambiental, menciona que tal Estado, além da necessidade de ser um Estado

\footnotetext{
${ }^{4}$ Tradução livre: "Na verdade, a modernidade é responsável por uma razão reducionista que, em nome das certezas, banaliza a complexidade, deixando o homem na condição de um observador alienado, que acredita na posse do conhecimento completo" (WARAT, 1997, p. 56).
} 
de Direito, deve primar por princípios voltados para a democracia, ${ }^{5}$ e para bem estar da sociedade, exigindo uma constante atualização legislativa à harmonização da defesa do ambiente (TEIXEIRA, 2006, p. 206-207). Ademais,

[...] o equilíbrio ambiental depende diretamente da sustentabilidade da sociedade compreendida no seu todo, o que depende de atos políticos de grande envergadura, capazes de reorientar o desenvolvimento econômico para a expansão das forças produtivas da sociedade com o objetivo de alcançar simultaneamente os direitos plenos da cidadania para toda a população e a manutenção do equilíbrio ecológico (CERVI; CERVI in GIMENEZ; LYRA [Orgs.]., 2016, p. 75).

Depreende-se que a sustentabilidade acima referida não compreende apenas a sustentabilidade ambiental ecológica, mas também uma sustentabilidade em outras esferas que se interligam com a ambiental como a sustentabilidade econômica, cultural dentre outras e,

Desta forma, o desenvolvimento sustentável representa a construção de importantes contribuições para uma relação mais harmoniosa entre o homem e o meio ambiente, constituindo-se em uma estratégia de passagem do paradigma hegemônico para o paradigma ecológico que emerge a partir de considerações atualizadas no âmbito da ciência, da ética e do Direito (CERVI; CERVI in GIMENEZ; LYRA [Orgs.]., 2016, p. 75).

No entanto para a presente discussão é conveniente mencionar a Declaração do Rio sobre Meio Ambiente e Desenvolvimento, no ano de 1992, em seu princípio no 20 , elenca a importância da mulher para com o cuidado e uma perpetuação do meio ambiente ecológico: “As mulheres têm um papel vital no gerenciamento do meio ambiente e no desenvolvimento. Sua participação plena é, portanto, essencial para se alcançar o desenvolvimento sustentável” (ONU,1992). Ao que pese o fato de parecer que o peso maior de proteção está voltado às mulheres, o reconhecimento destas no processo de desenvolvimento é simbolicamente singnificativo. A relação das mulheres com elementos do meio ambiente natural tem propiciado tal reconhecimento. A Diretriz $\mathrm{n}^{\circ} 20$, da ECO-92, ${ }^{6}$ é também um reflexo da luta das mulheres campesinas. Importa para uma melhor compreensão do texto no próximo tópico, o estudo da ecologia política como uma eco-cidadania em Warat.

\footnotetext{
${ }^{5}$ Em A Ciência Jurídica e deus Dois Maridos "O Direito esconde a democracia" (WARAT, 1985, p. 35).

${ }^{6}$ Desta Conferência, surgiram diversos documentos importantes: a Agenda 21; a Convenção da Biodiversidade; a Convenção das Mudanças Climáticas; a Carta da Terra e a Declaração do Rio sobre Ambiente e Desenvolvimento.
} 


\section{A ECOLOGIA POLITICA COMO UMA ECO-CIDADANIA WARATIANA}

A importância da recuperação da ética ecológica e do compromisso com uma responsabilidade maior com o conhecimento que foi repassado, com o cuidado com o planeta terra temas esses já presente no mundo das mulheres. Do mesmo modo o Papa Francisco em sua encíclica, no capítulo IV vem a cuidar de "Uma Ecologia Integral que inclua claramente as dimensões humanas e sociais", na qual vem a refletir, "E isto exige pensar e discutir acerca das condições de vida e de sobrevivência de uma sociedade, com a honestidade de pôr em questão modelos de desenvolvimento, produção e consumo" (PAPA FRANCISCO, 2015, p. 113).

O teórico Henrique Leff preconiza em relação a ecologia política, ${ }^{7}$ assim contribuindo de modo expressivo: “[...] a distribuição ecológica compreende os processos extra-econômicos (ecológicos e políticos) que vinculam a economia ecológica à ecologia política, em analogia com o conceito de distribuição que transfere a racionalidade econômica para o campo da economia política" (LEFF, 2001, p. 67).

Deste modo, se compreende a ecologia política como uma teoria em estágio inicial, a formação de um novo saber do pensamento crítico e de ação política, que se indaga sobre as transformações recentes da condição humana e sua existência, é um campo de estudo e prática que ainda não possui nome próprio, tomando emprestado conceitos e terminologias de outras áreas do conhecimento para a nomeação de diversos conflitos provenientes de uma desigual distribuição e apropriação de recursos naturais, bens e serviços ambientais (LEFF, 2006b, p. 22). Entende-se que a ecologia política adentra em diferentes áreas, principalmente nas esferas econômica e política, isso devido a exemplo, de um desastre ecológico poderá a vir atingir diferentes ambientes e grupos de pessoas como ocorre no meio ambiente transfronteiriço, assim, adentrando necessariamente nessas esferas de discussão. Em Warat, situa-se o termo "ecopolítica", onde descreve-o como "Meu uso do termo ecopolítica tem a ver com a ideia de que o homem pelo fato de haver nascido tem uma sede de direitos que precisam ser forçosamente reconhecidos e o que me corresponde" (WARAT, 2010, p. 44).

\footnotetext{
${ }^{7}$ A expressão ecologia política obteve um maior destaque em 1972, por Eric Wolf (antropólogo), muito embora esta já havia sido mencionada em 1957 por Bertrand de Jouvenel (MARTÍNEZ-ALIER, 2007, p. 110).
}

Revista Brasileira de Filosofia do Direito| e-ISSN: 2526-012X| Porto Alegre | v. 4 | n. 2 |

p. 57 - 72 | Jul/Dez. 2018 
Nesta proporção Félix Guattari, em sua obra As Três Ecologias, ${ }^{8}$ traz um olhar transversal, em qual

A subjetividade, através de chaves transversais, se instaura ao mesmo tempo no mundo do meio ambiente, dos grandes agenciamentos sociais institucionais e, simetricamente, no seio das paisagens e dos fantasmas que habitam as mais íntimas esferas do indivíduo. A reconquista de um grau de autonomia criativa num campo particular invoca outras reconquistas em outros campos (GUATTARI, 1990, p. 55).

Corroborando com este debate, Luís Alberto Warat propõe uma nova alternativa, onde indica “[...] a denominação 'eco-cidadania' como referência globalizante de uma resposta emancipatória sustentável, baseada na articulação da subjetividade em estado nascente, da cidadania em estado de mutação e da ecologia no conjunto de suas implicações" (WARAT, 1994, p. 98, grifo original). Para o mesmo, a resposta para os conflitos gerados é que a nova concepção seja uma fórmula para a reaprendizagem do mundo, calcado em três formas para avaliar: "[...] a ecologia, a cidadania e o desejo" (WARAT, 1994, p. 98, grifo original). Referente ao desejo, o sistema capitalista assenta os seres humanos em seu beneficio, propondo modelos de desejos, em prol de um dever e de uma única verdade, portando em seu centro a propriedade (WARAT, 1985, p. 31). Ainda, sobre a eco-cidadania em Warat,

\begin{abstract}
A 'eco-cidadania' desenvolveria idéias e práticas destinadas a inventar maneiras cotidianas de ser, novas micro e macro maneiras coletivas de viver, buscaria formas de aceitação da alteridade e os vínculos. Nada de um modelo de sociedade pronto para usar, apenas uma eco-ética e uma eco-estética, cujos objetivos estariam ligados com a instauração de valores não derivados do lucro ou do consumo. Uma 'pátria existencial' que privilegiaria o sentimento como produtor da realidade social, o sentimento como interesse coletivo (WARAT, 1994, p. 99, grifo da autora).
\end{abstract}

Luís Alberto Warat ensina que a eco-cidadania necessita estar nos valores não advindos de uma sociedade consumerista e de lucratividade, mas numa existência que favorecem os sentimentos humanos para criar novas realidades sociais e esses sentimentos devem ser tomados pela coletividade/sociedade. Para o mesmo, "O ideológico sempre foi bandeira de luta" e o grande capital "[...] quebra com todos os vínculos rurais tradicionais,

\footnotetext{
${ }^{8}$ Obra em qual insere a inovação do termo "Ecosofia" correspondente a um ético-política entre o meio ambiente, as relações sociais e a subjetividade humana (GUATTARI, 1990, p. 8).
} 
forçando o êxodo massivo rumo às grandes cidades" e o mesmo objetiva destruir não apenas os vínculos, mas também as identidades, indo além de uma exclusão social induzindo perdas referenciais identitárias (WARAT, 2010, p. 18- 19, grifo original). Por isso são necessárias novas alternativas como solução, proposta por Warat, ou seja, a eco-cidadania.

Temos, então, uma formulação original da 'eco-cidadania' como uma ecologia política do desejo, que ressalta a instância da subjetividade como condição reguladora de todos os seus circuitos semióticos. Quer dizer, uma 'eco-cidadania' que busca a totalidade de seu pensamento com a referência às questões da subjetividade: a ecologia e a cidadania vistas também como instâncias de realização da subjetividade: uma cartografia do desejo como potência de vida, transformadora das condições de existência e construtora da realidade: o desejo como produtor de novas conexões: o feminino por excelência (WARAT, 1994, p. 100).

Uma questão muito interessante nas teorias de Warat, e que tem a ver com o estudo, é que ele traz a perspectiva de gênero, relacionado-a ao tema referente a eco cidadania. Ele ressalta a existência de “[...] uma vinculação estreita entre a 'eco-cidadania' e a questões de gênero; isto é, a interpelação recíproca do masculino e do feminino como 'condição redefinitória' do sentido da ecologia, da cidadania e da subjetividade" (WARAT, 1994, p. 100). Perspicaz a postura de Warat, observando a questão da responsabilidade e do cuidado como condição pertinente a todos os gêneros humanos. Assim também ocorre com o movimento das mulheres camponesas ao que tange suas lutas e reivindicações de cunho ecológico, que estão em construção contínua, voltadas para uma eco-cidania de alteridade e emancipação. Assim, a seguir será analisado o Movimento das Mulheres Camponesas voltado para a eco-cidadania.

\section{O MOVIMENTO DAS MULHERES CAMPONESAS E A ECO-CIDADANIA}

Neste mesmo advento da eco-cidadania, se encontra o Movimento das Mulheres Camponesas no Brasil (MMC), ${ }^{9}$ um movimento social que também carrega os mencionados objetos de análise de Warat (a ecologia, a cidadania, o desejo) e, conforme o qual "Três

\footnotetext{
${ }^{9}$ O movimento das mulheres rurais surge nos anos de 1980, através de diferentes movimentos no campo, Estados brasileiros, construindo sua própria organização. Sua motivação por lutar pelos seus diretos,fora erguida pelo reconhecimento tanto econômico como identitário, ou seja, pela valorização como trabalhadoras rurais, lutando por uma libertação, por sindicatos, acesso a documentos pessoais de identificação, como por direitos trabalhista, previdenciários e uma maior participação política (LA VIA CAMPESINA MOVIMENTO CAMPESINO INTERNACIONAL, 2011, s. p).
} 
pontos de vista que, funcionando integrados (como 'eco-cidadania), permitirão recompor os objetivos do conjunto dos movimentos sociais (como redes) nas condições irreversíveis da transmodernidade (o homem nunca voltará a ser o que era na modernidade) (WARAT, 1994, p. 98, grifo da autora).

Para Leff, "Na cena política estão surgindo novos movimentos sociais que articulam a defesa do ambiente e dos recursos com suas lutas pela democracia, pela autonomia e a autogestão" (LEFF, 2001, p. 72). Frente ao caos ambiental sistêmico, a visão de desenvolvimento sustentável defendida pelas mulheres camponesas contesta a interpretação liberal sobre o desenvolvimento sustentável, o qual privilegia aspectos econômicos em oposição aos sociais, dos indivíduos e do ecológico, defendida, de modo especial por teorias ecofeministas. $^{10} \mathrm{O}$ ecofeminismo traz uma nova compreensão de qualidade de vida, pressupondo modelos de desenvolvimento calçados em padrões polêmicos de condução social, em Estados com uma modelagem do capital patriarcal. Alícia Puleo, a partir dos estudos de Andrew Dobson, demonstra a necessidade de uma nova moldagem uma compreensão de cidadania, partindo de uma cidadania ambiental, voltada ao âmbito público e que corresponda as perspectivas liberais, entretanto abrangendo também a cidadania ecológica desenvolvida tanto na esfera pública quanta na privada, objetivando uma não territorialidade ecológica e um maior comprometimento da coletividade (PULEO, 2013, p. 270-271). Neste debate de eco-cidadania, surge a figura das mulheres, como já abordado, anteriormente, em especial a Diretriz nº 20 da ECO/92, relacionando-as como mais próximas à natureza.

Alguns aspectos econômicos liberais e do patriarcado assumem uma postura de desenvolvimento sustentável não sistêmico: "Somente quando aprendermos a ligar nossas histórias e lutas, de um modo concreto e autêntico, com as das mulheres do lado inferior do atual sistema de poder e lucro, poderemos começar a ter uma idéia do que significa a teologia e a ética ecológica" (RUETHER, 2000, p.17). Rosemary Ruether, destaca a realidade de um contingente enorme de mulheres que sofrem com as crises ambientais:

Precisamos manter em mente, firmemente, a realidade destas mulheres, que carregam nos braços a criança que morre de desidratação por causa da água poluída;

\footnotetext{
${ }^{10} \mathrm{O}$ termo ecofeminismo aparece pela primeira vez na França, nos discursos de Françoise D’Eaubonne, em 1974, surgindo assim os primeiros manifestos do movimento feminista na defesa do meio ecológico e, em 1978, o mesmo fundou o movimento denominado "Ecologia e Feminismo" (BIANCHI, 2012, p. 01-26). Sandra Duarte de Souza afirma que esse movimento "[...] sintetiza duas preocupações: a ecológica e a feminista. Ele pressupõe que existe uma conexão entre a dominação da natureza e a dominação da mulher” (SOUZA, 2000, p. 57).
} 
que caminham longas horas para atender as necessidades básicas; e que continuam a lutar para atender as necessidades básicas; e que continuam a lutar para defender a vida com uma tenacidade que se recusa a ser derrotada e celebra com uma plenitude de espírito que desmente a aparente desesperança da situação (RUETHER, 2000, p. 17).

No atual cenário do desenvolvimento capitalista, estão inseridos os discutes ecológicos conjuntamente com a contenda das mulheres. A teóloga latino-americana Ivone Gebara, pondera que o ecofeminismo visa uma recuperação e valorização de ecossistemas ecológicos e das mulheres em uma conjuntura social em que as mesmas " [...] foram relegadas pelo sistema patriarcal e particularmente pela modernidade a serem força de reprodução de mão de obra, 'ventres benditos', enquanto a natureza tornou-se objeto de dominação em vista do crescimento do capital" (GEBARA, 1997, p. 10). Ivone Gebara reforça que as mulheres, de modo particular, as que se encontram em condição econômica menos privilegiada, são as mais atingidas pela crise ambiental, não pela existência próxima com a natureza, mas pelos laços de poder patriarcal totalitário praticada pelos homens em relação a natureza e as mulheres, afastando-as dos recursos e serviços ambientais, incidindo nos corpos das mulheres as ameaças, riscos e necessidades primordiais a vida, conferidos por desastres ecológicos e um desenvolvimento capitalista que privilegia a esfera econômica (GEBARA, 1997, p. 1416).

Para o jurista argentino Luís Alberto Warat, "Este é o projeto de globalização neoliberal: submeter à servidão a todos os outros; imigrantes, mulheres, e todos os excluídos que se submetem aos construtores da torre ou ficam como inimigos, que obstaculizam a construção e devem ser aniquilados pelas mais poderosas armas de guerra" (WARAT, 2010, p.10, grifo da autora).

As mulheres camponesas também lutam pelo mesmo desejo waratiano, "O desejo, ecosóficamente falando, vincula-se com todas as formas da vontade de viver, da vontade de criar, da vontade de amar e de inventar uma outra sociedade (enquanto percepção do mundo e ordem de valores)" (WARAT, 1994, p. 99). O cuidado com meio ambiente natural de forma sistêmica é uma forma ideológica de conceber a eco-cidadania e, neste caso, o ecofeminismo, independentemente de suas tendências, tem sido uma teoria que se baseia em ações concretas capazes de produzir resultados concretos. No ensinamento waratiano, 
As preocupações quanto ao sentido da vida estão estreitamente vinculadas à necessidade do cuidado de si mesmo. Seria a emergência de um estilo de existência inteiramente novo, dominado pelo cuidado de si mesmo. Individuos que se disponham a cuidar-se de todas as formas de maus tratos: em relação ao meio ambiente, ao poder e ao afeto. A ecologia como cuidado da vida; a cidadania como cuidado frente aos poderes que fundamentam a exploração e a alienação; a subjetividade como cuidado que permite liberar os afetos oprimidos (WARAT, 1994, p. 101).

Assim, merecido é o destaque da figura das mulheres camponesas, que por meio de sua luta nos movimentos do campo, transmutam nos valores/princípios enquanto organização: “[...] Respeitar as diferenças; Ética; Disciplina; Construir novas relações; [...] solidariedade; Amor à luta; Companheirismo; Valorização da mulher e de todos os seres humanos [...]" (MOVIMENTO DE MULHERES CAMPONESAS, s.a, s.p.), construindo a força necessária para se articularem em prol da emancipação feminina e ao mesmo tempo conseguem se manter fortes e unidas, buscando "A cidadania como um reclamo ético-estético-político por uma melhor qualidade da vida social; a possibilidade de algo mais digno para o conjunto de uma sociedade" (WARAT, 1994, p. 102, grifo da autora).

Frente ao Movimento de Mulheres Camponesas e a eco-cidadania, a gerencia da Lei e dos aparatos jurídicos, segundo a esteira waratiana, existiria "Uma exigência de ética, de justiça e de estética que não podem ser simplesmente reduzidas à instância instituída do Direito" (WARAT, 1994, p. 105), a qual representaria “[...] um 'plus' de ética, de justiça e de estética que necessitam ser referidos aos (não) lugares à que estão sendo condenados o social, o político e o subjetivo [...]. Os (não) lugares que a 'eco-cidadania' tem que problematizar em termos de desejo de autonomia (dos homens entre si e consigo mesmo)" (WARAT, 1994, p. 105). É neste contexto que as mulheres camponesas buscam ocupar os (não) lugares e se colocar em posições de fala e de serem ouvidas, rompendo com os antigos paradigmas culturais, sociais e sexistas. Ocupando esses (não) lugares para a promoção da cidadania e democracia.

Os (não) lugares encontram-se intimamente relacionados a biopolítica da esteira de Giorgio Agamben, colaborando nesta mesma ordem "Todas as regulações limitativas de meus direitos derivados da nua vida outorgam ao sentido de biopolítica um traço totalitário. Que vai agravando quando se introduz na relação política-vida a ideia de que existem vidas que não merecem, são indignas de serem vividas" (WARAT, 2010, p. 44), como ocorre com a vida das mulheres. 
O filósofo italiano Roberto Espósito, através dos seus estudos, a partir de Foucault, remonta a segunda modernidade em que vem determinar as dinâmicas políticas e a vida humana, entendida em sua condição especificamente biológica (compreendida também pelas mulheres). Naturalmente, pode-se observar que a política teve relação com a vida: a vida no sentido biológico, constituindo um marco material em que a política, necessariamente se inscreve (ESPOSITO, 2009, p. 126). Segundo Michel Foucault,

[...] o interesse a cujo princípio a razão governamental deve obedecer são interesses individuais e coletivos, a utilidade social e o benefício econômico, entre o equilíbrio do mercado e o regime do poder público, é um jogo complexo entre direitos fundamentais e independência dos governados. O governo, em todo caso o governo nessa nova razão governamental, é algo que manipula interesses ${ }^{11}$ (FOUCAULT, 2008, p. 61).

Assim como o governo manipula os interesses, também manipula o interesse sobre os corpos das mulheres pelos homens, sendo que ao lado da biopolítica situa-se também o controle social, pois a biopolítica é uma forma de controle dos interesses. $\mathrm{Na}$ seara de disciplinar os corpos, seguindo o viés da biopolítica de Giorgio Agamben, é possível interpretar uma política da vida e sobre a vida, inclusive adotando-se a interpretação tanatológica. ${ }^{12}$ A biopolítica traz a tona qual vida merece sobreviver e qual não merece o mesmo destino. Cabe aqui um paralelo entre a cultura do poder de dominação cultural masculino sobre as mulheres, estas que são, segundo o autor apenas zoé (uma vida nua) em que os homens insculpem sua cultura dominadora (AGAMBEN, 2002, p. 16). Na reflexão waratiana a cidadania e as instituições que promovem a justiça seriam as próprias violadoras de Direitos Humanos através de práticas biopolíticas como um biopoder (WARAT, 2010, p. 45) inserindo seus contextos hegemônicos em vidas nuas, em especial aos corpos femininos.

$\mathrm{Na}$ orda jurídica de Warat "O Direito pensado sem pensar nas normas de um modo reducionista. O Direito pensado como fantasia da esperança: um saber que estimule a criação de novos vínculos e valores" (WARAT, 1994, p. 105), promovendo uma eco-cidadania também na alteridade como um novo devir social e formado por uma democracia plural e não unitária (WARAT, 1985, p. 25). Warat como um suspiro de lamento e esperança, como uma

\footnotetext{
${ }^{11}$ Conforme Michel Foucault, “[...] os interesses são, no fundo, aquilo por intermédio do que o governo pode agir sobre todas as coisas que são, para ele, os indivíduos, os atos, as palavras, as riquezas, os recursos, a propriedade, os direitos, etc" (FOUCAULT, 2008, p. 61).

12 Tanatologia como ideia de higienização ver em Giorgio Agamben, em suas obras Homo Sacer: o poder soberano e a vida nua, p. 09-20 e Estado de Exceção, p. 09-20.
} 
nova forma de pensar e se posicionar, de que o social está num barco a deriva tanto em nível nacional quanto no exterior, que todos estão absortos nessa deriva, restando como salvação um filete de esperança, a eco-política na alteridade (WARAT, 2010, p. 16) e como manipuladores do Direito é imprescindível aprender a escutar o Direito, que está na rua e nas vozes que vem da mesma (WARAT, 2010, p. 53).

\section{CONCLUSÃO}

Um aspecto importante a ser mencionado é o fato do desenvolvimento sustentável dentro do contexto contemporâneo que prima pelo desenvolvimento econômico, situação essa denunciada pelos movimentos de mulheres camponesas e que buscam posicionar-se para alcançar direitos de igualdade, respeitando as diferenças, e isto tem sido bom porque elas pautam demandas de mudança cultural e jurídica das relações sociais e econômicas, voltadas para um desenvolvimento humano, cultural e econômico mais ecológico.

No caso das mulheres, aspectos esses trabalhados via a eco-cidadania como alteridade, desejo e emancipação, no desenvolvimento de uma ecopolítica que prime pela interação de diferentes esferas, dentre as quais a ecológica, política, econômica, social dentre outras, se opondo ao grande sistema de capital predatório e elevando a discussão para um novo patamar ideológico e prático, abarcando as mulheres, o que veio a ser reforçado pela "incumbência" da diretriz no 20 da Rio-92.

As mulheres, organizadas em movimentos sociais, como a partir do Movimento das Mulheres Camponesas brasileiras, apresentam preocupações semelhantes de Warat, também buscando a eco-cidadania como alteridade e emancipação, o desejo para uma melhor qualidade de vida em seu meio social, laboral, econômico e político. As mulheres do movimento desejam reescrever a sua história, não desejam e nunca desejaram que seus corpos servissem de superfície de uma escrita totalitária, não atendendo mais a condição de zoé. Importa a emancipação das mulheres camponesas a partir do momento em que elas ocupam os (não) lugares na sociedade, necessitam cada vez mais ocupar esses espaços a partir da presença e do lugar da fala (do espaço público) para integração de uma democracia mais ativa.

Revista Brasileira de Filosofia do Direito| e-ISSN: 2526-012X| Porto Alegre | v. 4 | n. 2 |

p. 57 - 72 | Jul/Dez. 2018 
O Direito como aporte jurídico e político, necessita se reinventar e reinterpretar, não podendo ser um barco a deriva, necessitando escutar os gritos que vem da rua, neste caso o clamor que advém das mulheres do campo.

\section{REFERÊNCIAS}

AGAMBEN, Giorgio. Homo sacer: o poder soberano da vida nua. 1. Trad. Henrique Burigo. Belo Horizonte: UFMG, 2002.

AGAMBEN, Giorgio. Estado de exceção. Trad. Iraci D. Poleti. Título original: "Estato di eccezione". São Paulo: Boitempo, 2004.

BOBBIO, Norberto. A Era dos Direitos. Trad. Carlos Nelson Coutinho. Rio de Janeiro: Elsevier, 2004.

BRASIL, 1988. Constituição da República Federativa do Brasil de 1988. Disponível em: <http://www.planalto.gov.br/ccivil_03/constituicao/ConstituicaoCompilado.htm>. Acesso em: 05 Set. 2017.

CERVI, Jacson Roberto; CERVI, Taciana M. Damo "O paradigma ecológico e a contribuição do direito para a superação da dicotomia meio ambiente e desenvolvimento". In: LYRA, José Francisco Dias da Costa; GIMENEZ, Charlise Paula Colet [Orgs.]. Diálogo e Entendimento: direito e multiculturalismo \& políticas de cidadania e resoluções de conflito: tomo 7. Campinas: Millennium Editora, 2016.

CMMAD (Comissão Mundial sobre Meio Ambiente e Desenvolvimento). Nosso Futuro Comum . 2 ed. Rio de Janeiro: Ed. FGV, 1991.

ESPOSITO, Roberto. Comunidad, immunidad y biopolítica. Título Original: “Termini dela politica. Comunità, immunità, biopolitica". Trad. Alicia García Ruiz. España: Herder, 2009.

FIORILLO, Celso Antônio Pacheco. Curso de direito ambiental brasileiro. 15 ed. São Paulo: Saraiva, 2014.

FLORES, Bárbara Nascimento; TREVIZAN, Salvador Dal Pozzo. "Ecofeminismo e comunidade sustentável”. In: Estudos Feministas. Universidade Federal de Santa Catarina. Centro de Filosofia e Ciênci as Humanas, Centro de Comunicação e Expressão. v. 7, n.1-2. Florianópolis: UFSC, 1999.

FOUCAULT, Michel. Nascimento da biopolítica: curso dado no College de France (19781979) ; Titulo original: "Naissance de la biopolitique"; edição estabelecida por Michel Senellart; sob a direção de François Ewald e Alessandro Fontana; Trad. Eduardo Brandão; Rev. da trad. Claudia Berlinex. Coleção Tópicos. São Paulo: Martins Fontes, 2008. 
GEBARA, Ivone. Teologia Ecofeminista. São Paulo: Editora Olho d'Água, 1997.

GUATTARI, FÉLIX. As três ecologias. Título original : Les trois écologies. Trad. Maria Cristina F. Bittencourt. Campinas, SP: Papirus, 1990.

LA VIA CAMPESINA MOVIMENTO CAMPESINO INTERNACIONAL. Jornada da via campesina mobiliza 10 estados contra os agrotóxicos. Disponível em:

$<$ https://viacampesina.org/es/index.php/temas-principales-mainmenu-27/mujeres-mainmenu39/1121-jornada-da-via-campesina-mobiliza-10-estados-contra-agrotoxicos $>$. Acesso em 23 de set. 2016.

MARTÍNEZ-ALIER, Joan. O ecologismo dos pobres: conflitos ambientais e linguagens de valoração. Trad. Maurício Waldman. São Paulo: Contexto, 2007.

LEFF, Enrique. Saber ambiental: sustentabilidade, racionalidade, complexidade, poder. Tradução de Lúcia Mathilde Endlich Orth. Petrópolis, RJ: Vozes, 2001.

LEFF, Enrique. La ecología política em América Latina: un campo em construcción. In: ALIMONDA, Héctor (Org.). Los Tormentos de La Materia: aportes para uma ecología política latinoamericana. Buenos Aires: Consejo Latinoamericano de Ciências Sociales, 2006. p. 21-39.

LEFF, Henrique. Ecologia, capital e cultura, a territorialização da racionalidade ambiental. Trad. Jorge E. Silva. $2^{\text {a }}$ ed. Rio de Janeiro: Vozes, 2009.

LEITE, José Rubens Morato. "Sociedade de risco e Estado". In: CANOTILHO, José Joaquim Gomes; LEITE, José Rubens Morato [Orgs.]. Direito constitucional ambiental brasileiro. $5^{\text {a }}$ ed. ver. São Paulo: Saraiva, 2012.

MOVIMENTO DE MULHERES CAMPONESAS. História. Disponível em:<http://www.mmcbrasil.com.br/site/node/44>. Acesso em: 12 Jul. 2017.

PULEO, Alícia H. "Feminismo y Ecología". In: El Ecologista. n. 31. El Ecologista, no 31, verano 2002. Disponível em:<

https://www.fuhem.es/media/cdv/file/biblioteca/Boletin_ECOS/10/feminismo_y_ecologia.pdf >. Acesso em: 02 Set. 2017.

PULEO, Alicia H. Ecofeminismo para outro mundo posible. $2^{\mathrm{a}}$ ed. Madrid, Spain: Instituto de la mujer, Ediciones Cátedra, Universitat de Valência, 2013.

SARLET, Ingo Wolfgang. A eficácia dos direitos fundamentais. 7 ed. ver. atual. ampl. Porto Alegre: Livraria do Advogado, 2007.

SARLET, Ingo Wolfgang; FENSTERSEIFER, Tiago." Estado socioambiental e mínimo existencial (ecológico?):algumas aproximações". In: SARLET, Ingo Wolfgang [Org.]. Estado socioambiental e direitos fundamentais. Porto Alegre: Livraria do Advogado, 2010, p. 11-38.

Revista Brasileira de Filosofia do Direito | e-ISSN: 2526-012X| Porto Alegre | v. 4 | n. 2 |

p. $57-72$ | Jul/Dez. 2018 
SARLET, Ingo Wolfgang; FENSTERSEIFER, Tiago. Direito ambiental: introdução, fundamentos, e teoria geral. São Paulo: Saraiva, 2014, p. 37-146.

SOUZA, Sandra Duarte. "Teoria, teo(a)logia e espiritualidade ecofeminista: uma análise do discurso”. Revista Mandrágora: Revista de Estudos de Gênero e Religião. Núcleo de estudos teológicos da mulher na América Latina/ do Curso de Pós-Graduação em Ciências da Religião da Universidade Metodista de São Paulo (UMESP) e do Instituto Ecumêmico de PósGraduação em Ciências da Religião. São Bernardo do Campo, SP: UMESP, Ano VI. n.6, p. 57-64, dez. 2000.

RUETHER, Rosemary Radford. "Ecofeminismo: mulheres do primeiro e terceiro mundos". Revista Mandrágora: Revista de Estudos de Gênero e Religião. Núcleo de estudos teológicos da mulher na América Latina/ do Curso de Pós-Graduação em Ciências da Religião da Universidade Metodista de São Paulo (UMESP) e do Instituto Ecumêmico de Pós- Graduação em Ciências da Religião. São Bernardo do Campo, SP: UMESP, Ano VI. n.6, p. 11-17, dez. 2000 .

PAPA, Francisco. Carta Encíclica Laudato si' sobre o cuidado da casa comum. $1^{\mathrm{a}}$ ed. $4^{\mathrm{a}}$ reimpressão. São Paulo: Paulinas, 2015.

TEIXEIRA, Orci Paulino Bretanha. O direito ao meio ambiente ecologicamente equilibrado como direito fundamental. Porto Alegre: Livraria do Advogado, 2006.

WARAT, Luís Alberto. A ciência jurídica e seus dois maridos. Santa Cruz do Sul: Faculdades Integradas de Santa Cruz do Sul, 1985.

WARAT, Luís Alberto. "Eco-cidadania e direito: alguns aspectos da modernidade, sua decadência e transformação". Tradução de Jose Luis Bolzan de Morais. In: Revista Seqüencia N. 28 Ano 15, junho de 1994 - p. 96-110. Disponível em:<

http://www.egov.ufsc.br/portal/conteudo/eco-cidadania-e-direito-alguns-aspectos-damodernidade-sua-decad\%C3\%AAncia-e-transforma\%C3\%A7\%C3\%A3o>. Acesso em: 01 Ago. 2018.

WARAT, Luís Alberto. Semiotica ecologica y derecho: los alredores de una semiótica de la mediación. Argentina; Florianópolis: Associación Latinoamericana de Mediación Metodologia y Enseñanza Del Derecho, 1997.

WARAT, Luís Alberto. A rua grita Dionísio! Direitos humanos da alteridade, surrealismo e cartografia. Trad. e Orgs. Vívian Alves de Assis, Júlio César Marcellino Jr e Alexandre Moaris da Rosa. Rio de Janeiro: Lumen Juris, 2010. 